ISSN: 2792-3967

D0l: https://doi.org/10.5370I/shj.v2il.36

\title{
EL DILEMA DEL COMITÉ INTERNACIONAL DE CRUZ ROJA: LA NEUTRALIDAD ANTE EL GENOCIDI0
}

\author{
THE DILEMMA OF THE INTERNATIONAL COMMITTEE OF THE RED CROSS. NEUTRALITY TOWARDS THE GENOCIDE
}

\author{
Fernando Navarro García \\ Instituto de Estudios para la Ética y la responsabilidad \\ Social de las Organizaciones (INNOVAÉTICA) \\ ORCID: 0000-0003-4057-I37X \\ f.navarro.64@gmail.com \\ fernando.navarro@innovaetica.org
}

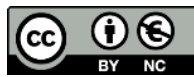

\section{| Resumen |}

Este artículo analiza la posición adoptada por el Comité Internacional de la Cruz Roja (CICR) contra los crimenes nazis de los que fue testigo entre 1933 a 1945 y más específicamente su "política de silencio" - fundada en el principio humanitario de neutralidad - en lo que respecta al Holocausto. La acción humanitaria del CICR no fue fácil durante el periodo analizado, no solo porque carecia de muchos recursos esenciales para actuar eficientemente a nivel de campo en un conflicto que desbordó cualquier previsión de horrores, sino también porque la mera presencia de esta organización fue considerada por algunos beligerantes (Alemania nazi, pero también la URSS y el imperio japonés) como una "interferencia" en su forma de desarrollar la guerra. La segunda parte de este artículo revisa la actividad de la Cruz Roja durante los años del terror nazi: el marco ético y juríico principal del CICR antes de la Segunda Guerra Mundial (Convenios de Ginebra y los principios humanitarios), la evolución de los crímenes nazis y las actividades principales del CICR y lo que realmente conocian sobre la existencia Genocidio. Finalmente, expondremos las razones que explican la política de silencio del CICR y el impacto que tal actuación ha tenido en la evolución de la Cruz Roja.

Palabras clave: Cruz Roja; Holocausto; Nazismo; Genocidio; Neutralidad; Humanitarismo.

\section{Abstract}

This article analyzes the position taken by the International Committee of the Red Cross (ICRC) against the Nazi crimes that it witnessed between 1933 to 1945 and more specifically its "politics of silence" - based on the humanitarian principle of neutrality - in the Regarding the Holocaust. The humanitarian action of the ICRC was not easy, not only because it lacked many essential resources to act efficiently at the field level in a conflict that exceeded any forecast of horrors, but also because the mere presence of this organization was considered by some belligerents (Germany Nazi, but also the USSR and the Japanese Empire) as an "interference" in their way of handling the war. The second part of this article reviews the activity of the Red Cross during the years of the Nazi terror: the main ethical and legal framework of the ICRC before the Second World War (Geneva Conventions and humanitarian principles), the evolution of Nazi crimes and the ICRC's main activities and what they really knew about the Holocaust. Finally, we will explain the ICRC's reasons for its silence policy and the impact that such a policy has had on the evolution of the Red Cross.

Keywords | (Thesaurus): Red Cross; Holocaust; Nazism; Genocide; Neutrality; Humanitarism.

${ }^{1}$ Recibido/Received: 19/10/2021

Aceptado/Accepted: 21/0I/2022

SHJ, 2022, 2(I), pp. I28-I52. ISSN: 2792-3967 


\section{| Introducción |}

El Derecho Internacional Humanitario (en adelante DIH) es el conjunto de normas que regulan la conducta durante los conflictos armados por razones de humanidad y para paliar los daños que produce el empleo extremo de violencia (Ortega, 2014). Aunque tradicionalmente habían existido algunas reglas consuetudinarias basadas en normas aceptables de combate, la sensibilidad hacia las consecuencias de la guerra se acentuó a finales del siglo XIX gracias a la creación de la Cruz Roja, regida por principios de humanidad y neutralidad entre otros. El auge de los totalitarismos de entreguerras $y$, sobre todo, el inicio de la Segunda Guerra Mundial y el exterminio sistemático de la población judía europea supuso una ruptura con las formas clásicas de combate y enfrentó a la Cruz Roja ante un enorme dilema ético al tener que elegir entre dos de sus principios rectores fundamentales: humanidad y neutralidad. A pesar de la ingente labor humanitaria del Comité Internacional de la Cruz Roja (en adelante CICR) durante el conflicto, la organización ha sido cuestionada (Farré, 2012; Slim, 2001) por su posición durante el Genocidio. Algunas acciones como la reunión de octubre de 1942 en Ginebra (Favez, 1989 y 1999; Vonèche Cardia, 2012) o la visita en 1944 del delegado del CICR al campo de tránsito de Terezin (Farré y Schubert, 2009, p. 65-83) han sido calificadas por algunos autores de "error moral" (Mathur, 2008; Warner, 2005, p. 459). En este artículo vamos a analizar el dilema ético afrontado por el CICR y sus decisiones más controvertidas, $y$ lo haremos contextualizando con los criterios legales y morales de la época (periodo de entreguerras y Segunda Guerra Mundial) y sobre la base del análisis de algunos hechos y documentos fundamentales para entender las decisiones del ClCR.

\section{| La protección de las víctimas de los conflictos: EI CICR y los principios humanitarios |}

La Cruz Roja fue fundada en 1863 por Henry Dunant, un empresario suizo y un idealista humanitario consciente del sufrimiento de las víctimas de la guerra tras recorrer el campo de batalla de Solferino (1858). En 1863 Dunant contempló dos categorías de "no combatientes" cuyo sufrimiento debería aliviarse al amparo de los primeros Convenios de Ginebra de la Cruz Roja: los prisioneros de guerra y los náufragos, heridos y enfermos. No en vano, las victimas mayoritarias de las guerras de mediados del siglo $\mathrm{XIX}$ eran militares, con un escaso porcentaje de víctimas civiles. Se estima que la ratio porcentual de víctimas civiles y militares en los conflictos de la era napoleónica es de 10$90 \%$, antes de la Primera Guerra Mundial las víctimas civiles representaban el 16\%, durante la Segunda Guerra Mundial la cifra de víctimas civiles aumentó al 65\% mientras que en los conflictos contemporáneos las víctimas civiles son el $90 \%$ y las militares un $10 \%$ del total de víctimas (RICR, 1991, p. 327) ${ }^{2}$.

${ }^{2}$ Texto completo del artículo: https://international-review.icrc.org/fr/articles/campagne-mondiale-pour-la-protection-des-victimesde-la-guerre-0 (web consultada: 25/01/2021). 
La iniciativa de Dunant fue el primer paso para el desarrollo del DIH que se ha ido construyendo desde entonces hasta hoy a través de los sucesivos Convenios de Ginebra, muy especialmente tras la Segunda Guerra Mundial. Aunque en la actualidad están vigentes cuatro Convenios de Ginebra (todos de 1949) y dos Protocolos adicionales (1977), que abarcan una amplia gama de "no combatientes" (incluidos los civiles en la Convención IV), debe tenerse en cuenta que antes de la Segunda Guerra Mundial solo existían dos Convenciones de Ginebra, siguiendo la pauta marcada por el fundador del CICR de focalizarse en las victimas militares $y$ no tanto en las civiles dadas las características ya señaladas de los conflictos armados de aquel periodo histórico. Téngase en cuenta que el año anterior al de la aprobación de las dos Convenciones de Ginebra se había firmado el Pacto Briand-Kellog en virtud del cual las potencias "renunciaban a la guerra como instrumento de política nacional" (Sandoz, 2007, p.184). El 27 de agosto de 1928 quince naciones (incluidas Alemania, Italia y Japón) habían firmado el Tratado de París - más conocido como Pacto Briand-Kellog - mediante el cual se "prohibía la guerra como mecanismo de resolución de conflictos". Solo una década más tarde se pudo confirmar que el voluntarismo del Tratado de París fue inútil para frenar la agresión totalitaria del nazismo y también del comunismo estalinista ${ }^{3}$ :

En cuanto estos últimos países firmaron el pacto, los estadistas de todo el mundo empezaron a tener sus dudas. Francia condicionó su propuesta original, incluyendo una cláusula que legalizaba las guerras en defensa propia y las destinadas a cumplir con las obligaciones contraídas con el Pacto de la Sociedad de Naciones, las Garantías de Locarno y todas las alianzas de Francia. Esto llevó la situación a su punto de partida, pues las excepciones incluían todo caso concebible. A continuación, Gran Bretaña insistió en tener libertad de acción para defender su Imperio. Las reservas de los Estados Unidos fueron las más generales de todas. (Kissinger, 1996)

Finalmente, en la Conferencia Diplomática de 1929 fueron aprobadas las Convenciones I y II de Ginebra:

- Convención para la protección de heridos y enfermos (1929) 4 .

- Convención para la protección de prisioneros de guerra (1929) 5 .

Sin embargo, ninguna de las dos Convenciones de 1929 preveía la protección de la población civil. Esta omisión que hoy puede resultar sorprendente tiene sentido si consideramos que los Convenios de Ginebra fueron concebidos a finales del siglo diecinueve cuando las principales víctimas de la guerra eran los soldados heridos o

\footnotetext{
${ }^{3}$ El Pacto Nazi-Soviético o Pacto Ribbentrop-Mólotov de 23 de agosto de 1939 y posteriormente el Tratado Alemán-Soviético de Amistad, Cooperación y Demarcación de 28 de septiembre de 1939 que incluía un protocolo secreto con cuatro artículos en donde se acordaba el reparto de Polonia con el rio Vístula como frontera entre ambos totalitarismos y la ocupación de la URSS de los Estados Bálticos, Finlandia y Besarabia, como así sucedió durante los primeros meses de la guerra y en donde se produjeron numerosos crímenes de guerra por parte de ambas naciones agresoras (matanza de las fosas de Katyn por parte soviética).

Convención para la protección de heridos y enfermos (1929). Disponible en: https://ihldatabases.icrc.org/applic/ihl/ihl.nsf/Treaty.xsp?documentld=09DFB7A98E19533AC12563CD002D6997\&action=openDocument

(web consultada 5 de diciembre de 2021).

Convención para la protección de prisioneros de guerra (1929). Disponible en: https://ihldatabases.icrc.org/applic/ihl/ihl.nsf/INTRO/305? OpenDocument (web consultada 5 de diciembre de 2021)
} 
presos. Para entender esta laguna normativa, debe tenerse en cuenta que el clima de la época (Pacto Briand-Kellog) hacía poco factible la inmediatez de un nuevo conflicto mundial y aun así en la Conferencia Diplomática de 1929 se recomendó realizar un "estudio exhaustivo" que abordara la protección de los civiles con nacionalidad de potencia enemiga residentes en el territorio de una de las partes beligerantes o en territorios ocupados.

El panorama cambiaría radicalmente tras el inicio de las hostilidades de la Segunda Guerra Mundial (en adelante, SGM) pues a partir de ese conflicto la población civil contabilizó el mayor número de víctimas durante la guerra (genocidio o Shoá, bombardeo sistemático de ciudades, deportados, desplazados y refugiados, violaciones sistemáticas, toma de rehenes, etc. $\left.{ }^{6}\right)$. Sin embargo, en 1929 nadie fue capaz de prever esta terrible amenaza.

\section{|El Borrador de Tokio y los primeros intentos para proteger a la población civil en los conflictos armados |}

Es justo reconocer que el CICR, bajo la crucial presidencia de Max Huber (1928-1944), propuso un borrador para una nueva convención que protegería a los civiles en caso de conflicto armado. Los tiempos cambiaban rápidamente y también las armas, los métodos de combate y el propio desarrollo de las hostilidades (Guerra Civil española, invasión italiana de Etiopia, invasión japonesa de China, etc.), razón por la cual el CICR hizo todo lo posible para intentar amparar también a la población civil en caso de conflicto. Sin embargo, los intentos del CICR no llegaron a cristalizar antes del estallido de la SGM en septiembre de 1939. A pesar de sus esfuerzos, el CICR solo consiguió elaborar un borrador de convenio el 29 de octubre de 1934, más conocido como Borrador de Tokio y cuyo nombre completo es Convención para la protección de la población civil de nacionalidad enemiga que se encuentre en territorio perteneciente $u$ ocupado por alguno de los beligerantes ${ }^{7}$. El documento tenía dos problemas sustanciales que desprotegían a un alto número de civiles.

El primer problema es que sus 33 artículos solo aludían a la protección de los "civiles enemigos", esto es, de aquellos residentes en un país en conflicto que eran nacionales de otros países enemigos (es decir, alemanes que vivían en el Reino Unido, japoneses que residían en Estados Unidos, etc.). Según el Borrador de Tokio la población civil de "nacionalidad enemiga" tenía la consideración de prisionero de guerra, lo que supuso que durante la Segunda Guerra Mundial más de 160.000 "civiles enemigos" de 50 naciones distintas quedaron de alguna forma "amparados" por este borrador ${ }^{8}$. Sus condiciones no siempre fueron fáciles y la forma en que fueron gestionados los campos

\footnotetext{
6 Antes del inicio de la Segunda Guerra Mundial están documentados algunos crímenes de guerra contra la población civil (bombardeos de Guernica en 1937 y Cabra en 1938 durante la Guerra Civil española, masacre de Nankín en 1937, etc.) pero no dejan de ser operaciones militares inmediatamente anteriores al estallido del conflicto y en algún caso preparatorias del mismo. Acceso al Proyecto de Tokio en web de CICR (consultada 30 de junio de 2021): https://ihldatabases.icrc.org/ihl/INTRO/320?OpenDocument.

Solamente en los Estados Unidos, y entre 1942 y 1948, fueron concentrados en campos de prisioneros 120.000 ciudadanos norteamericanos de origen japonés.
} 
de "civiles enemigos" por algunas de las partes en conflicto ha sido muy cuestionada, pero en general se respetaron los estándares humanitarios mínimos propugnados por el CICR (dieta adecuada, agrupación familiar, comunicación con familiares en el extranjero, prohibición de malos tratos, trabajos forzados o ejecuciones sumarísimas, etc.).

El segundo problema o limitación del Borrador de Tokio es que no contempló a la "población civil no enemiga del propio Estado beligerante". En otras palabras, el borrador no protegió a los "delincuentes comunes" o a aquellos calificados como tales, como fue el caso de los judíos y otros colectivos perseguidos durante el Tercer Reich. EI CICR no pudo prever que la actuación de algunos Estados (básicamente las potencias del Eje en los territorios ocupados) fuese dirigida contra sus propios ciudadanos, como fue el caso de la persecución y posterior extermino por parte del régimen nacionalsocialista de judíos y gitanos, pero también de los Testigos de Jehová, comunistas, homosexuales, objetores de conciencia o discapacitados allá donde fuesen encontrados en los territorios del Gran Reich. Para dificultar aún más las cosas, el Tercer Reich consideró a los judíos como "civiles detenidos" bajo una peculiar interpretación y aplicación de la "custodia preventiva" (Schutzhäftlinge'), lo que automáticamente los excluyó de cualquier convención internacional al ser una competencia policial estrictamente interna y ajena a las hostilidades entre las distintas potencias.

Los nazis rechazaban el Código Penal de 1871 y el Código Civil alemán de 1900 a los que consideraban "orientales y judaizantes”, razón por la cual en 1935 una comisión de Derecho Penal —dirigida por el ministro de justicia Franz Gürtner (Navarro, 2010, p. 232-233) inició los trabajos para armonizar la copiosa y dispersa legislación nazi para promulgar un nuevo Código Penal que finalmente no llegó a aprobarse. Freisler, el juez de los Tribunales Populares nazis instó a los jueces a abandonar la imparcialidad y juzgar "sólo con espíritu nacionalsocialista" (Navarro, 2010, p. 178-179), algo que quedó legalmente consagrado con la aprobación de las llamadas leyes de Núremberg (15 de septiembre de 1935). El padre de tales leyes raciales que eliminaron gradualmente a los judíos de la economía y la vida pública alemanas y que condujeron a la Shoá, fue el ministro del Interior Wilhelm Frick, quien en 1935 ya había enviado alrededor de 100.000 opositores del régimen y otros Schutzhäftlinge a los campos de concentración (Navarro, 2010, p. 180). El estallido de la guerra no hizo más que agravar la perversión de la justicia nazi y los crímenes cometidos en su nombre, muy especialmente contra los judíos. Por esta razón, durante los Procesos de Núremberg (discurso de apertura en el Juicio “The United States of America vs. Josef Altstotter, et al”), el fiscal jefe - general de brigada Telford Taylor -afirmó que "el puñal del asesino se ocultó bajo el manto del jurista" ${ }^{10}$.

\footnotetext{
${ }^{9}$ Schutzhäftlinge aludía a aquellas personas arrestadas por razones políticas, raciales o de cualquier otro tipo que fuese interpretado por las autoridades como una "amenaza para el Estado". No eran detenidas por la comisión de un delito sino por el simple hecho de pertenecer a un colectivo considerado como una amenaza, de ahí la "custodia preventiva".

${ }^{10}$ Estados Unidos de América vs. Josef Altstoetter et al., militar Tribunal III, Caso 3, Juicios de criminales de guerra ante los Tribunales Militares de Núremberg. Bajo Control de la Ley $\mathrm{N}^{\circ} 10$ del Consejo, Núremberg, octubre 1946 a abril 1949, vol. III. Washington, 1951.
}

SHJ, 2022, 2(I), pp. 128-152. ISSN: 2792-3967 
Pero la responsabilidad no cabe restringirla al nazismo, al menos en cuanto a la comisión por omisión. El propio CICR, en su afán por mantener su neutralidad y evitar conflictos con los Estados beligerantes, llegó a acuñar en 1919 el término "detenidos a causa de los acontecimientos" para referirse a los prisioneros políticos en la Hungría comunista de Bela Kun (Moreillon, 1973, p. 655-661). De este modo cuando un gobierno afrontaba una crisis o conflicto interno el CICR insistió en tratar de intervenir a través de las Sociedades Nacionales de la Cruz Roja (en adelante SNCR), normalmente un apéndice político del Estado al que representaban y, en consecuencia, escasamente neutrales. Por ejemplo, cuando en los años veinte el CICR intentó intervenir en el violento conflicto irlandés, el CICR contactó con la Cruz Roja Británica quien informó al CICR que "no existía ningún conflicto armado dentro del Reino Unido, ni razones para que Ginebra se preocupara por los acontecimientos en Irlanda". Este es el mismo modus operandi que siguieron algunas SNCR bajo la hégira totalitaria y que, como veremos, resultó nefasto en la siguiente década al afrontar el problema de los "presos políticos" alemanes bajo el régimen nacionalsocialista (Forsythe, 2005, p. 38).

El Borrador de Tokio nunca llegó a ser aprobado en la Conferencia Diplomática prevista por el Gobierno suizo para 1940, pues el inicio de las hostilidades paralizó cualquier proyecto humanitario (Sandoz, 2007, p. 185). Ello no fue óbice para que el CICR continuara intentando recabar acuerdos internacionales para la creación de "zonas seguras" para proteger a la población civil (especialmente mujeres, niños y ancianos) o la prohibición de bombardeos indiscriminados, tal y como propuso en su $16^{\circ}$ Conferencia Internacional de la Cruz Roja (Londres, 20 al 24 de junio de 1938). En las postrimerías de la SGM no existía, por lo tanto, ninguna convención que protegiera expresamente a la población civil y Max Huber - anticipándose a los problemas que tal vacío podía crear - decidió que el CICR tendría que actuar aplicando la analogía sobre la base de las convenciones existentes, tal y como se desprende de una circular enviada a SNCR en 1939 (Circular 365 a las SNCR, 20 de abril de 1939, citado por Sandoz, 2007, p. 186).

\section{| La nazificación de la Cruz Roja Alemana (DRK) |}

La Cruz Roja Alemana (Deutsches Rotes Kreuz, en adelante DRK), en calidad de asociación médica y social fue "sincronizada" por el Estado nazi como lo fue toda la profesión médica bajo el Tercer Reich a partir de 1933. Se entiende por "sincronización" (Gleichschaltung) el proceso paulatino y velado de nazificación de la sociedad alemana a través del control y cooptación de todas las instituciones, empezando por la educación y las organizaciones de trabajadores. Se trata de un término derivado de la mecánica que también puede traducirse como "puesta a punto" o "coordinación" (Navarro, Sichar y Cuerda, 2018, p. 189) y que explica parcialmente la escasa resistencia cívica o institucional a la marea nazi en sus primeros momentos.

Como hemos visto, no debe confundirse la DRK con el CICR. La DRK, aunque federada y siendo parte del Movimiento Internacional de la Cruz Roja, mantenía estatutariamente 
una total independencia del CICR, lo que permitió que tras la llegada al poder de los nazis la DRK pudiera actuar en abierta contradicción con los principios humanitarios propugnados por el CICR, tal y como veremos más adelante.

En muy pocos años la medicina alemana pasó de la esterilización a los asesinatos médicos directos de las "vidas sin valor" o "indignas de ser vividas". Tales crímenes fueron calificados como "muertes por compasión" con ese disimulado uso del lenguaje por el Tercer Reich. Los doctores fueron considerados por el régimen nazi como "soldados biológicos de guardia”. Prueba de la implicación de la profesión médica (Cuerda, 2016; Navarro et al, 2019, p. 413-441) con la genocida cosmovisión nazi es que durante los Procesos de Núremberg (Juicio de los Doctores) fueron juzgados 24 médicos por haber cometido crímenes contra la humanidad ${ }^{11}$.

El propio presidente de la DRK, duque de Sajonia-Coburgo (nombrado en diciembre de 1933), anunció en mayo de 1936 la "transformación de la DRK según los principios nacionalsocialistas” (Moorehead, 1998, p. 356). No es de extrañar esta declaración en quien era un nacionalista convencido desde inicios de los años veinte, miembro del NSDAP desde marzo de 1933 y Obergruppenführer (equivalente a General) de las SA.

A partir de 1938 la DRK pasó a ser totalmente controlada o "sincronizada" por el aparato del partido nacionalsocialista, dependiendo directamente del Ministerio para la Organización del Bienestar Social Interior, dirigido por Ernst-Robert Grawitz y con el apoyo de Oswald Pohl (jefe del departamento económico y administrativo de las SS). El Dr. Grawitz - desde entonces presidente en funciones de la DRK - fue al mismo tiempo jefe de los Servicios de Salud de la SS y de la Policía, lo que da una idea de su implicación con el nazismo. Grawitz fue también editor de Doctores Eternos, un panfleto seudomédico muy relevante en el proceso de nazificación del ethòs médico y desde cuyas páginas se instaba a erradicar de la profesión todo atisbo de "compasión exagerada" para con los débiles. Durante la presidencia de facto del Dr. Grawitz (el duque de SajoniaCoburgo se mantuvo como presidente de iure pero en realidad sin funciones ejecutivas) los trabajadores de la DRK adoptaron el saludo y emblemas nazis, fueron adoctrinados en los principios e ideología nacionalsocialista (racismo, eugenesia, eutanasia, herencia biológica, etc.) y hasta recibieron instrucción militar (Morgenbrod y Merkenich, 2008, p. 115-116).

El proceso de sincronización llegó a su punto álgido en 1942, cuando el presidente en funciones de la DRK recomendó a Himmler el uso de las cámaras de gas como el mejor método para llevar a cabo los asesinatos sistemáticos de judíos en todos los territorios del Reich. Incluso el Zyklon-B con el que se empezó a exterminar masivamente a los judíos en los campos de exterminio fue transportado hasta los campos de la muerte en vehículos de la Cruz Roja Alemana controlada por el Dr. Grawitz (Moorehead, 1998, p. 468; Rees, 2017, p. 405). Asimismo, llegó a emplearse pérfidamente el propio emblema

\footnotetext{
${ }^{11}$ La cifra real de personal sanitario juzgado y sentenciado por crímenes de guerra es muy superior, aunque no existe un registro claro, habida cuenta de los distintos procesos judiciales desarrollados en Alemania y otros países: Juicios de Núremberg (1945-46) y Procesos de Frankfurt (1963-65). En la actualidad se está en desarrollando en Alemania un proceso de revisión histórica de algunos nombres emblemáticos de la medicina y la investigación por su filiación y colaboración con el nazismo, tales como Hugo Spatz, Hallervorden o Reiter.
} 
de la Cruz Roja en hospitales ficticios para transmitir a las víctimas una falsa sensación de protección al ver el símbolo de la Cruz Roja en los muros de Sobibór en los que inmediatamente eran asesinadas (Rees, 2017, p. 384).

En paralelo a este proceso de sincronización en la cúspide del organigrama de la DRK, los gauleiters - gobernadores locales nazis - asumieron la jefatura de las asociaciones locales de enfermería, de tal manera que los experimentos raciales promovidos por Himmler (por ejemplo, las Lebensborn o "fuentes de vida") fueron legitimados moralmente al contar con el apoyo de la DRK. En este periodo se pueden encontrar numerosas publicaciones en su revista Deutsche Rötes Kreuz con titulares tan significativos como "Alemania necesita nuevos y pequeños bebés de ojos azules para alzar el Reich alemán". Por si todavía tales experimentos eugenésicos suscitaran algunas dudas entre la profesión médica o la propia sociedad alemana, la mayoría de los artículos raciales publicados en la revista solían estar plagados de citas de Mein Kampf.

Desde la culminación de la sincronización en 1938, la cooperación de la DRK con el CICR fue prácticamente inexistente. Sin embargo, en 1938 el presidente del CICR aún tenía la esperanza de poder intervenir a favor de la población civil alemana perseguida por el nazismo - muy especialmente los judíos - mediante el dialogo y las negociaciones discretas con el Gobierno alemán, como lo prueban las cartas enviadas por Max Huber a la DRK el 29 de noviembre y 28 de diciembre de 1938 reclamando su intervención en apoyo de "los judíos enfermos y abandonados" (Sandoz, 2007, p. 191). Poco después, en enero de 1939, el CICR envió otra carta a la DRK para volver a inquirir si estaban haciendo algo por las familias judías indigentes. Su lacónica respuesta fue: "la DRK no ha hecho nada y no ve ni la posibilidad ni la necesidad de desarrollar acción alguna" (Moorehead, 1998, p. 363). Recordemos que los propios Estatutos del CICR (en vigor desde el 26 de octubre de 1928) no contemplaban la anulación de la membresía de una SNCR una vez que ésta ya había sido aprobada por el CICR; ni siquiera en aquellos casos en los que la sociedad nacional no respetara los principios básicos humanitarios del CICR ya que las SNCR eran "independientes y autónomas" (Sandoz, 2007, p. 179). El propio Huber, en su mensaje durante la Conferencia Internacional de Tokio de 1934 llegó a afirmar que la Cruz Roja al prestar desinteresadamente su ayuda "deseaba trabajar con cualquier otro que anhelara ayudar a otros, sin preguntarles por sus motivaciones para actuar ${ }^{12}$ ".

\section{| Los principios humanitarios y el dilema ético del CICR |}

La esencia de una organización humanitaria como el CICR no es solamente la de aliviar el dolor de las víctimas sino hacerlo sobre la base de unos principios humanitarios, operativos y éticos (Pérez de Armiño, 2002, p.13-16; Pictet, 1966). Actuar sobre la base de esos principios es lo que hoy conocemos como "espacio humanitario", ya que una ayuda sustentada, por ejemplo, en un interés geoestratégico o militar al servicio de los intereses de un gobierno - y por lo tanto parcial y no neutral - no puede ser considerada como ayuda humanitaria. Sin duda es ayuda, pero no "humanitaria". En la actualidad,

${ }^{12}$ Huber, Max. Revue Internationale de la Croix-Rouge, No. 192, Dec. 1934 (citado por Sandoz, 2007, p. 182) 
tales principios se recogen en los Estatutos del Movimiento Internacional de la Cruz Roja y en el Código de Conducta Relativo al Socorro en Casos de Desastre ${ }^{13}$ de 1994 y son los siguientes:

- Principio de humanidad o de acción benefactora: dicta que "lo primero es el deber humanitario (...) obligación de prestar asistencia humanitaria, doquiera sea necesaria"14. Este principio se concreta en aliviar el dolor de las víctimas de los conflictos y en tratarlas con el respeto que merece su dignidad como seres humanos.

- Principio de neutralidad: dicta que "con el fin de conservar la confianza de todos, el Movimiento se abstiene de tomar parte en las hostilidades y, en todo momento, en las controversias de orden político, racial, religioso y filosófico". Con este principio se pretende evitar dar la impresión de favoritismo u hostilidad hacia alguna de las partes en conflicto. La neutralidad no lo es hacia el sufrimiento sino hacia las causas que lo motivan y, por lo tanto, es una estrategia operativa y un medio para poder desempeñar en la práctica el principio básico de humanidad (Macrae, 1996, p. 2736).

- Principio de independencia significa que la intervención humanitaria se desempeñara sobre la base de las propias decisiones de la organización, al margen de condicionamientos políticos tanto en sus países de origen como en los que actúe. Veremos más adelante que este principio fue erosionado por la ambigua relación política y financiera del CICR con el Gobierno suizo durante la SGM.

- Principio de imparcialidad que es el principio que concreta el deber de justicia e implica el deber de no discriminación por razones de raza, religión, política, nacionalidad, historia, etc. Toda vida humana tiene valor y por lo tanto hay que dar a cada víctima según su necesidad, por lo tanto, la ayuda se proporciona a las víctimas en función de sus necesidades y no sobre la base de otros criterios que supongan discriminación de raza, sexo o ideología política. Paradójicamente, este fue el principio esgrimido por el CICR para no cuestionar la exclusión de los judíos de la DRK a partir de 1936 (Favez, citado por Sandoz, 2007, p. 183; Mathur, 2008, p. 7).

- Principio de autonomía: dicta que la ayuda debe servir a la autonomía del beneficiario. En otras palabras, no se puede hacer el bien sin contar con aquel a quien se pretende hacer el bien.

- Principio de transparencia que implica que las organizaciones humanitarias son responsables ante aquellos a quienes tratan de ayudar $y$ ante las personas o las instituciones de las que aceptan recursos.

Sin embargo, estos principios - que actualmente son internacionalmente aceptados y aplicados por la mayoría de las organizaciones humanitarias (no solamente por el CICR) - no estaban codificados antes de la SGM, esto es, no estaban plasmados en un documento escrito de carácter programático, sino que existían como principios generales consuetudinarios que podían ser interpretados según las circunstancias. Tampoco se diferenciaba claramente durante el periodo de entreguerras entre derechos

\footnotetext{
Código de Conducta Relativo al Socorro en Casos de Desastre (1994). Disponible en: https://www.icrc.org/spa/resources/documents/misc/64zpm8.htm (web consultada: 5 de diciembre de 2021)

${ }^{14}$ Artículo 1 del Código de Conducta Relativo al Socorro en Casos de Desastre (CICR, 1994).
} 
humanos y DIH (Mathur, 2008, p. 8) y, de hecho, los principios humanitarios no se positivaron hasta la Conferencia Internacional de la Cruz Roja de Viena en 1965 (Pérez de Armiño, 2002, p. 13). Durante las últimas décadas, y especialmente en la post-Guerra Fría, tales principios se han visto cuestionados y sometidos a un proceso de revisión desde el propio CICR, esencialmente a causa de los dilemas éticos que había afrontado la acción humanitaria durante la SGM.

Un dilema ético es aquella situación en la que un agente debe tomar una decisión "incómoda" sobre la mejor acción a adoptar e independientemente de qué acción se tome, en la decisión siempre se compromete o vulnera algún principio ético. Ante un dilema ético no hay una solución perfecta, pues siempre se habrá causado algún mal. Un dilema ético supone un razonamiento disyuntivo que expresa la necesidad de elegir entre dos valores morales mutuamente incompatibles (Blázquez, Devesa del Prado y Cano, 1999, p. 159).

El dilema ético del CICR durante la SGM fue decidir si debían o no denunciar públicamente los crímenes nazis de los que, como veremos, fueron conocedores desde 1933. Creemos que este dilema ético solo puede evaluarse a la luz de los principios del CICR que estuvieron vigentes entre 1933 y 1945. Kant considera que los valores y principios son una especie de "brújula ${ }^{15}$ moral" (Kant, 1921) que guía u orienta los objetivos de las organizaciones y por esta razón antes de analizar la posición del CICR frente al genocidio revisaremos brevemente cuáles eran sus principios rectores en aquel momento.

Recordemos que en 1939 el CICR no disponía de una Carta de Principios por escrito. Como hemos visto, dicho documento solo existirá a partir de 1966, tras la Conferencia de Viena. En los años treinta, el CICR no tenía la necesidad de establecer sus principios internos por escrito y funcionaban consuetudinariamente, sobre la base de los criterios morales interpretados por el Comité y muy especialmente por su influyente presidente. Comité y presidencia basaban sus decisiones en la experiencia acumulada y en la tradición transmitida oralmente por sus predecesores (Sandoz, 2007, p. 176). Max Huber fue presidente del CICR desde 1929 hasta 1944 y, por lo tanto, sus creencias y su moral personal fueron la "brújula moral" del CICR durante ese largo y crítico período de nuestra historia.

\section{| El influjo moral de Max Huber en las decisiones del CICR |}

En 1923, Max Huber fue admitido por el CICR en su Asamblea, siendo la primera vez en la historia de este organismo en que un no ginebrino (nació en Zürich, en 1974) era aceptado en este importante órgano decisorio. En los años veinte del pasado siglo, la Asamblea era esencialmente un organismo poco profesionalizado, integrado por un

\footnotetext{
${ }^{15}$ Al final del capítulo I de la Fundamentación de la Metafísica de las Costumbres Kant escribe su conocida metáfora de la brújula ("compás" en la traducción de García-Morente): "Sería muy fácil mostrar aquí cómo, con este compás en la mano, sabe distinguir perfectamente en todos los casos que ocurren qué es bien, qué es mal, qué es conforme al deber o contrario al deber, cuando, sin enseñarle nada nuevo, se le hace atender solamente, como hacía Sócrates, a su propio principio, y que no hace falta ciencia ni filosofía alguna para saber qué es lo que se debe hacer para ser honrado y bueno, y hasta sabio y virtuoso".
} 
grupo de notables suizos, no siempre dispuestos a leer los informes y limitados a asistir a las pocas reuniones programadas, con el apoyo de una reducida plantilla de técnicos. En 1939, el personal administrativo del CICR en Ginebra era de tres personas (Durand, 1984, p. 413), lo que nos da una idea de los retos logísticos y operativos que la organización tuvo que afrontar una vez se iniciaron las hostilidades.

EI CICR a menudo operaba en áreas muy alejadas de Ginebra y para ello solía recabar el asesoramiento del Gobierno suizo o de algún empresario o expatriado - siempre suizo, siguiendo la tradición - en el área de conflicto. Las intervenciones que el CICR realizaba en el terreno solían delegarse en suizos residentes en el país de intervención humanitaria, personas que muy a menudo no contaban ni con la formación técnica ni con una idea precisa de los principios humanitarios que debían inspirar la ayuda. Max Huber a menudo estaba enfermo o fuera de Ginebra y durante sus ausencias fue Carl Burckhardt - otro conservador suizo-germano - quien asumía sus funciones (Forsythe, 2005, p. 41).

La literatura (Sandoz, 2007; Durand, 1984; Moorehead, 1988 y Favez, 1999) ha examinado los numerosos escritos y publicaciones de Huber antes y durante la SGM y en general se identifican tres ideas básicas que guiaron sus decisiones éticas y jurídicas y que, dado su prestigio e influencia, también inspiraron el posicionamiento del CICR:

1. El anhelo de consolidar un Movimiento de la Cruz Roja con carácter universal, lo que como ya se ha visto supuso una compleja diplomacia basada en el dialogo discreto entre el CICR y las distintas SNCR.

2. La contribución a la paz sobre la base de la promoción del derecho internacional humanitario (Sandoz, 2007, p. 185).

3. La política de discreción (neutralidad) y el tratamiento confidencial de las denuncias de presuntas violaciones del derecho humanitario (Favez, 1989, p. 45-56; Favez, 1999, y Vonèche Cardia, 2012).

De todas ellas, creemos que para comprender algunas de las acciones que el CICR adoptó frente al genocidio, la neutralidad y la política de discreción inspirada por Huber fueron determinantes, si bien solo pueden entenderse en su justa medida si relacionamos dicha interpretación del principio de neutralidad con el anhelo de Max Huber de universalidad de la Cruz Roja y con su férrea voluntad de luchar a toda costa por la paz.

En derecho internacional se entiende por neutralidad el estatus jurídico de un Estado que ha decidido mantenerse apartado de la guerra entre otros Estados, sin manifestarse política o ideológicamente en cuanto a las causas del conflicto. Cuando este principio se aplica a la acción humanitaria, supone la abstención de todo acto de ayuda que en cualquier situación conflictiva pueda interpretarse como favorable a una de las partes implicadas o en detrimento de la otra. La neutralidad, como hemos visto, supone no tomar partido en las hostilidades (no beligerancia), ni comprometerse en controversias políticas, raciales, religiosas o ideológicas (neutralidad propiamente dicha). La neutralidad humanitaria lo que implica es ser neutral no hacia el sufrimiento sino hacia la fuente del mismo. No es indiferencia, sino una estrategia operativa, un medio para desempeñar 
eficazmente el principio humanitario de acción benefactora de ayuda y protección de las víctimas (Pérez de Armiño, 2004, p. 14).

En 1934, Max Huber proclamó durante la Conferencia Internacional de Tokio que "la Cruz Roja de ninguna manera puede convertirse en un cuerpo extraño dentro de una nación o un Estado" y añadió que "no podía oponerse al sentimiento nacional, estatal o gubernamental por obra del cual había sido reconocida y autorizada para desarrollar sus funciones" ${ }^{16}$. Poco después, en su artículo de 1936 La Cruz Roja y la Neutralidad, Huber escribió (Huber, 1936, p. 353-363):

A diferencia de otros grupos libremente organizados, la Cruz Roja y el CICR deben ser muy precavidas y saber autocontrolarse. Y ello no por indiferencia o cobardía sino como parte de nuestra responsabilidad de evitar a todas las partes sospechas de parcialidad, política o de otro tipo.

En el mismo artículo Huber afirma:

EI CICR aspira a abolir o aliviar el sufrimiento humano (...) La neutralidad y la imparcialidad nunca deberían ceder bajo la presión de la pasión (...) nunca deberíamos comprometer el frágil edificio en el que tantas víctimas han encontrado refugio.

Algunos autores (Forsythe, 2005, p. 39) han mostrado que el CICR del periodo de entreguerras siempre mantuvo con el mismo rigor su principio de neutralidad, incluso a pesar del bombardeo con gases tóxicos durante la invasión italiana de Etiopia (19351936) o de los bombardeos de ciudades durante la Guerra Civil española (1936-1939). La historiadora de la Cruz Roja, Caroline Morehead, interpreta dicho silencio como una velada simpatía de Burckhardt - presidente en funciones del CICR - por el fascismo, al que a la sazón percibía como "un dique frente al bolchevismo" (Forsythe, 2005, p. 176).

Esta interpretación radical de neutralidad por parte de Max Huber se mantuvo intacta incluso cuando la persecución a los judíos alcanzó cotas brutales en Alemania: el 16 de noviembre de 1938, pocos días después de la Noche de los Cristales Rotos (Kristallnacht) Max Huber escribió: "En este momento, indudablemente angustioso, debemos mantener nuestra sang-froid". Ese mismo año 1938, crucial en la persecución de los judíos, Huber sentenció: "resulta esencial que el CICR no se vea involucrado en una acción política o se comprometa a no estar en condiciones de honrar" (Moorehead, 1998, p. 373).

En consecuencia, la interpretación de neutralidad propugnada insistentemente por Max Huber supuso que el CICR se autoimpusiera un alto grado de discreción, llegando incluso a ocultar - o no difundir- algunas de las pruebas del genocidio que habían recibido de sus propios delegados. $Y$ todo ello a pesar de que en situaciones extremas el CICR estaba facultado estatutariamente para ejercer su derecho de iniciativa (Mathur, 2008, p. 4).

${ }^{16}$ Huber, Max. Revue internationale de la Croix-Rouge, No. 192, Dec. 1934 (Citado por Sandoz, 2007, p. 182). 


\section{| El conocimiento del genocidio por parte del CICR |}

Al terminar la SGM y hacerse pública la enormidad del genocidio, el CICR empezó a ser cuestionado. Aunque su acción humanitaria durante la guerra fue indiscutiblemente positiva, su silencio ante los crímenes contra la humanidad de los que habían sido testigos requería una explicación. EI CICR no pudo alegar ignorancia sobre lo que había sucedido en la Alemania nazi desde 1933 o en los territorios ocupados por el III Reich a partir de septiembre de 1939. Existe una extensa bibliografía que desmenuza las cartas, informes y artículos de prensa custodiados en los archivos ginebrinos del CICR y de ellas se desprende claramente que el CICR recibía información regular y fidedigna que acreditaba que la intimidación y la represión nazi contra los judíos y otros grupos sociopolíticos iba aumentando cada día.

Aunque en aquel momento no existía un procedimiento preciso para efectuar las visitas a los campos de prisioneros, los delegados de la Cruz Roja hacía tiempo que seguían una meticulosa rutina que pasaba por concretar la visita con los comandantes de los campos de prisioneros, acopiar y documentar información sobre los prisioneros, inspeccionar minuciosamente las instalaciones (letrinas, comedores, etc.) y entrevistar a los prisioneros en privado para evitar represalias. El resultado de este trabajo de inspección independiente, imparcial y neutral culminaba con un informe confidencial que era presentado a los gobiernos implicados para que actuaran en consecuencia. Si no lo hacían el CICR se reservaba el derecho a una protesta pública. Asimismo, el CICR tenía la opción de publicar la totalidad del informe si consideraba que había sido manipulado o instrumentalizado políticamente por los gobiernos afectados, cuando, por ejemplo, se difundían únicamente los aspectos más positivos del informe al tiempo que se ocultaban los más críticos (Moorehead, 2005).

Pueden establecerse dos períodos diferentes durante los cuales el CICR fue siendo paulatinamente consciente de los crímenes del nazismo (Mooreheah, 1998):

a) Periodo de incertidumbre (1933 - 1941):

Como hemos visto, en los años treinta el CICR contaba con una estructura muy reducida, con menos de cincuenta colaboradores en 1939 y solo diecinueve de ellos en plantilla. En invierno de 1944 la cifra había alcanzado los 3.650, dos mil de los cuales eran voluntarios (ICRC 1948, p. 63) ${ }^{17} .150$ delegados eran los encargados de realizar las visitas a los campos de prisioneros en cinco continentes (Moorehead, 2005). Sin embargo, y a pesar de sus reducidos recursos humanos, el CICR supo gestionar miles de comunicaciones confusas y a menudo dudosas, realizar indagaciones, analizar denuncias y estudiar informes diversos sobre los crímenes nazis que más tarde asociaríamos al genocidio. A esta dificultad logística o instrumental hay que añadir la falta de cooperación de la DRK que, como hemos visto, había sido nazificada en 1934.

${ }^{17}$ El ICRC. Report of the International Committee of the Red Cross on its Activities during the Second World War (Geneva, 1948) consta de tres volúmenes. La paginación referenciada corresponde al volumen $\mathrm{n}^{\circ} 1$ 
No obstante, el CICR no era desconocedor de la persecución judía y de otros crímenes raciales y políticos cometidos por el régimen nazi. Según Favez (1999), el CICR abordó por vez primera la "creciente violencia política en Alemania" el 18 de mayo de 1933. Solamente durante los primeros seis meses de 1933, el CICR fue testigo - como el resto del mundo- de la apertura del campo de concentración de Dachau, la aprobación del "párrafo ario" (que excluía a los judíos del funcionariado ${ }^{18}$ ) o la legislación sobre la esterilización forzosa de pacientes con alguna discapacidad. Poco tiempo después, y tras la aprobación de Las leyes de Núremberg de 1935 no quedó ninguna duda sobre la naturaleza totalitaria del régimen nacionalsocialista ${ }^{19}$.

Moorehead, en su exhaustiva historia de la Cruz Roja, documenta algunos informes y comunicaciones sorprendentes del CICR que aluden a los crímenes nazis perpetrados entre 1933 y 1941 y que no dejan lugar a dudas a acerca del conocimiento de los hechos por parte de los máximos responsables del CICR:

- La primera visita del CICR a Dachau fue en octubre 1935. Burckhardt, director del CICR, se reunió personalmente con Carl Von Ossietzky, pacifista y ganador del Premio Nobel de la Paz que había sido condenado por los nazis por "alta traición". Según los registros de las visitas, todos los prisioneros con los habló pudo hablar Burckhardt le parecieron "asustados e incómodos; siendo sus respuestas evasivas" (Moorehead, 1998, p. 351-352). El mismo Burckhardt visitó ese mismo mes los campos de Lichtenburg y Esterwegen (Favez, 1999).

- Unos meses más tarde, en mayo de 1936, Burckhardt regresó a Alemania para reunirse con Heydrich (alto rango de las SS y principal arquitecto del genocidio) y con von Ribbentrop (futuro ministro de Asuntos Exteriores) para tratar sobre el estado de los prisioneros en los campos de concentración ${ }^{20}$. En su informe, detectó "mejoras reales", añadiendo además que "los programas para reformar a los comunistas funcionaban bien". Según el informe del CICR de 1936 "los detenidos judíos eran tratados exactamente igual que los prisioneros arios" y hasta "parecían sinceramente satisfechos". El 23 de junio de 1936, Burckhardt envió una carta a Hitler agradeciendo su "magnífica hospitalidad y excelente organización", gracias a la cual pudo "conocer algunos logros verdaderamente mágicos" (Moorehead, 1998, p. 350-358).

- En 1938 un delegado del CICR, Guillaume Favre, volvió a visitar Dachau (Favez, 1999) y, una vez más, su informe resultó aún más sorprendente: "En todas partes reina el orden, la limpieza e incluso una cierta elegancia". Sin embargo, la confusión del CICR a este respecto se acredita por las diversas cartas que Max Huber dirigió en 1938 (29 de noviembre y 28 de diciembre) a la DRK preguntándoles por su actuación para

\footnotetext{
${ }^{18}$ Ley de la Restauración de la Administración Publica, promulgada el 7 de abril de 1933.

19 Dos leyes distintas aprobadas en la Alemania nazi (el 15 de septiembre de 1935) se conocen colectivamente como las leyes de Núremberg: la Ley de Ciudadanía del Reich y la Ley para la Protección de la Sangre Alemana y el Honor Alemán. Estas leyes incorporaron muchas de las teorías raciales que sustentan la ideología nazi. Proporcionarían el marco legal para la persecución sistemática de judíos en Alemania.

${ }^{20}$ En 1936, Ribbentrop aún no era ministro de Asuntos Exteriores, aunque tenía un gran "prestigio" en Alemania como diplomático. En 1935, Ribbentrop organizó varias visitas propagandísticas de veteranos de la Primera Guerra Mundial a Gran Bretaña, Francia y Alemania. Las visitas de los veteranos y las promesas de "nunca más la guerra" hicieron mucho para mejorar la imagen de la "Nueva Alemania" en Gran Bretaña y Francia.
} 
con los judíos enfermos o prisioneros. El 9 de enero de 1939 la DRK declinó informar al CICR (Sandoz, 2007, p. 191).

- El 17 de agosto de 1940, tras el inicio de la conflagración, dos delegados del CICR, Pierre Descoeudres y Roland Marti, fueron autorizados a visitar Buchenwald (Favez, citado por Farré, 2012, p. 1388).

- En octubre-noviembre de 1939 el delegado del CICR, Marcel Junod, realizó un viaje de inspección a Alemania y a la Polonia ocupada (Junod, 1951). Ese mismo mes habían comenzado las deportaciones de judíos a Polonia (Lublin).

- En 1940 el CICR recibió un cable de Tel Aviv en el que se les preguntaba "si la congregación judía de Stettin había sido deportada" a lo que el CICR respondió con un "lamentamos no ser capaces de responder a esa pregunta, por quedar fuera del alcance de nuestra actividad" (Moorehead, 1998).

- El 20 de agosto de 1940 la DRK comunicó formalmente al CICR que suspendía todas sus indagaciones sobre los campos de concentración.

- En el otoño de 1941 el pastor Visser't Hooft - Secretario General del Consejo Ecuménico de Iglesias en Ginebra - escribió a Max Huber y a Burckhardt para exponerles claramente la existencia de "hambruna y tifus en el gueto de Varsovia" así como de los primeros deportados a los campos de exterminio. Prácticamente en las mismas fechas, en noviembre de 1941, el ministro suizo en Bucarest escribió a Jaques Cheneviére (CICR) describiendo las atrocidades cometidas contra los judíos en Rumania: "Las masacres contra los armenios fueron, en comparación, un juego de niños" (Moorehead, 1998, p. 418).

b) Periodo de evidencias (1942 - 1945):

Pero si desde finales de 1941, como hemos visto, el CICR ya poseía información suficiente y exhaustiva sobre violaciones y otros abusos del nazismo contra población civil no combatiente, no fue hasta octubre de 1942 cuando tomaron la decisión táctica de "guardar silencio" para poder seguir aliviando el dolor de las víctimas. Entre octubre de 1941 y 1942 el CICR fue conocedor de numerosos crímenes contra la humanidad del nazismo, ya que se trata del periodo álgido de la Shoá. La siguiente es una lista no exhaustiva de hechos relacionados con el genocidio conocidos por el CICR en este corto período (Vonèche Cardia, 2012; Favez, 1999 y Moorehead, 1998):

- 10 de abril de 1942: el informe de W. Rohmer a Burckhardt, presidente en funciones del CICR, alude directamente a "atroces masacres" y añadiendo que "en Ucrania habían sido asesinados unos 100.000 judíos". Existe una nota interna de Gallopin a Marti (16 de abril de 1942), preguntándole por el destino de los deportados al Este. Ese mismo mes, la Cruz Roja Alemana responde que no puede suministrar información sobre los detenidos "no arios" (Favez, 1999).

- Entre los días 2 y 9 de junio de 1942: varias menciones al campo de exterminio de Auschwitz - por entonces plenamente operativo como "industria de muerte" - por parte de la Cruz Roja Francesa y de la Cruz Roja Eslovaca. Esta última solicita expresamente el 9 de junio de 1942 la intervención del CICR y el 3 de septiembre el CICR responderá declinando dicha intervención. 
- Agosto de 1942: Gerhart Riegner, Secretario del Congreso Mundial Judío en Ginebra, había recabado pruebas suficientes acerca de la Solución Final y envió un informe completo a Burckhardt ${ }^{21}$. Como resultado de aquel informe, diversas SNCR solicitaron mayores detalles sobre la suerte de los judíos en Europa y el modo en que debían proceder con ellos, a lo que desde la dirección del CICR se respondió de forma ambigua o manifiestamente falsa, como demuestra la respuesta del CICR al Departamento de Estado estadounidense de 2 de noviembre de 1942:

EI CICR no cuenta actualmente con información suficiente acerca del destino de los judíos deportados a Polonia.

O a la Cruz Roja Británica de 19 de noviembre de 1941:

Se trata de una situación muy trágica pero no podemos hacer nada al respecto.

- Octubre de 1942: Jan Karski consiguió acceder dos veces al gueto de Varsovia y al campo de exterminio de Belzec haciéndose pasar por alemán. Su visita duró sólo una hora; suficiente para conocer de primera mano el exterminio sistemático. En Londres se entrevistó con Anthony Eden y otros líderes políticos que integraban el gabinete británico de guerra. Eden contestó que no podían hacer nada porque la estrategia aliada consistía en derrotar militarmente a Alemania y que ningún "asunto secundario" debía interferir el objetivo. La situación no mejoró en EEUU. En verano de 1943, Karski se entrevistó con Roosevelt y otras personalidades, pero sus informes tampoco fueron creídos. En 1944, Karski publicó Story of the Secret State e inició un ciclo de conferencias en los Estados Unidos para dar a conocer el exterminio. En 1987 escribió (Navarro, 2010, p. 364-365):

Después de la guerra leí cómo los líderes occidentales, hombres de estado, militares, servicios de inteligencia, jerarquías eclesiásticas y dirigentes civiles se horrorizaban por lo que había pasado con los judíos. Declaraban no haber sabido nada acerca del Holocausto pues el genocidio había sido mantenido en secreto. Esta versión de los hechos persiste todavía pero no es más que un mito. El exterminio no era un secreto para ellos.

- El 17 de diciembre de 1942, los aliados firmaron una denuncia conjunta de la "política bestial de exterminio a sangre fría contra los judíos que está llevando a cabo Alemania". Dos meses antes se había celebrado la reunión de Ginebra en donde el CICR acordó el pacto de silencio, como veremos en el siguiente epígrafe.

- El 23 de junio de 1944, el delegado del CICR Maurice Rossel visitó el campo de tránsito de Terezin. Su informe fue utilizado por la propaganda nazi como una prueba del trato "humanitario" a los deportados, tal y como veremos.

- El 14 de septiembre de 1944, Jean-Etienne Schwarzenberg, jefe de la División de Asistencia especial del CICR y máximo responsable de la ayuda a los deportados en los campos nazis, escribió a Chenevière que "la situación de los deportados y de los judíos en Alemania está siendo más precaria que nunca, ya que ahora se han convertido en testigos especialmente peligrosos" y urgió al CICR para que "revisara

\footnotetext{
${ }^{21}$ La solución final a la cuestión judía (en alemán: die Endlösung der Judenfrage) fue el plan nazi para el exterminio de los judíos en la Europa ocupada por los alemanes durante la Segunda Guerra Mundial. El plan, promovido por Heydrich, fue formulado en enero de 1942 en la Conferencia de Wannsee, una villa en las afueras de Berlín.
} 
su política de confidencialidad en vista de las actuales circunstancias" (Farré, 2012, p. 1391)

- A partir de enero de 1945 y ante la inminente derrota, Himmler y otros máximos responsables del genocidio (Kaltenbruner se reúne con Burckhardt el 12 de marzo de 1945) inician negociaciones secretas en Berlín con delegados de la Cruz Roja, lo que cristaliza en operaciones esporádicas y muy limitadas de intercambio de prisioneros. Para entonces la Shoá ya había alcanzado a seis millones de víctimas en toda Europa.

\section{| La reunión de Ginebra de octubre de 1942 y el pacto de silencio del CICR |}

Teniendo en cuenta los crímenes nazis que a mediados de septiembre de 1942 ya eran conocidos, veintiuno de los veintiséis miembros del comité del CICR se mostraron partidarios de realizar algún tipo de pronunciamiento público. Para discutir este importante asunto se convocó una sesión plenaria el 14 de octubre de 1942 en Ginebra. Solo había un punto en el orden del día: decidir si realizar o no un llamamiento público en defensa de los judíos de la Europa ocupada. La Solución final ya era conocida, gracias al Telegrama Riegner (8 de agosto de 1942) y a otras fuentes igualmente explícitas y desde el CICR se consideró necesario saber cómo actuar ante tales crímenes ${ }^{22}$.

Max Huber y Burckhardt preferían la "regla del silencio" para poder seguir trabajando en los campos de prisioneros, tal y como ya hemos visto que ambos se habían manifestado en ocasiones anteriores (Huber, 1936). Durante la reunión de Ginebra, Huber y Burckhardt contaron con el apoyo de Philippe Etter, otro prestigioso miembro del comité que consiguió suscitar las dudas de los compromisarios al plantearles qué pasaría si una de las principales potencias decidiera utilizar la denuncia del CICR como un mero instrumento de propaganda (Moorehead, 1998, p. 422). Aquella potencial amenaza a la neutralidad del CICR fue la razón principal que inclinó la balanza de los compromisarios en favor de una neutralidad radical fundada en la "discreción".

La decisión final, por lo tanto, fue la de guardar silencio para poder intervenir sobre el terreno ya que se entendió que "una denuncia pública pondría en peligro el trabajo que se estaba realizando con los prisioneros y heridos de guerra, que eran el verdadero mandato de la organización" (Moorehead, 1998), sobre la base de las dos convenciones de Ginebra de 1929. El CICR tras esta reunión de 1942 decidió pragmáticamente "no protestar, sino actuar". En palabras de Mathur el CICR decidió "no enfrentarse a la Gorgona” (Mathur, 2008, p. 7). Desde entonces, los miembros del CICR se obligaron por escrito a "observar la neutralidad más estricta en todo momento y lugar, a abstenerse de cualquier actividad de carácter político, confesional o comercial" y a seguir la "más estricta discreción, sin conceder entrevistas, en ningún lugar, a ninguna persona y en cualquier momento". El principio de neutralidad quedó desde entonces ligado operativamente a una rígida política de confidencialidad que era y es "un artículo de fe"

${ }^{22}$ Mensaje telegráfico de Gerhart Riegner, a la sazón Secretario del Congreso Mundial Judío (CMJ) en Ginebra, enviado a las oficinas del CMJ en Nueva York y Londres. 
para el CICR ya que, aunque la Cruz Roja "puede acceder a todo, no revelara nada" (Moorehead, 2005) ${ }^{23}$.

En otoño de 1944 - cuando la SGM estaba en su fase final - la Revista del Comité Internacional continuó sin aludir a los campos de exterminio nazis. No obstante, el propio Huber, por carta privada de 2 de octubre de 1944 dirigida a las autoridades alemanas, solicitaba que se "ampliaran los derechos de los presos preventivos" o Schutzhäftlinge (Farré, 2012, p. 1392), esto es, de los judíos entre otros.

\section{| La instrumentalización del humanitarismo por la propaganda nazi: la visita del CICR a Terezin |}

Terezin era un gueto amurallado y desde 1941 fue un "campo de tránsito" en Checoslovaquia (actual República Checa) que los nazis emplearon como instrumento de propaganda para "demostrar" internacionalmente su trato humanitario a los prisioneros y deportados judíos que allí se hacinaban. Por el campo de Terezín pasaron 144.000 judíos, de los cuales fueron deportados a Auschwitz y otros campos de exterminio más de 88.000. Al terminar la guerra solo 17.000 judíos del total de 144.000 que pasaron por Terezin habían logrado sobrevivir.

El 23 de junio de 1944, el Dr. Maurice Rossel, delegado del CICR adscrito a la oficina de Berlín, fue autorizado a visitar el campo de Terezin y en su breve informe de quince páginas concluyó que las condiciones de vida de los judíos allí concentrados eran excelentes. En su informe llegó incluso a afirmar que "en el campo de Terezin era posible conseguir productos y facilidades prácticamente inaccesibles en Praga". Para que la inspección del CICR fuese satisfactoria las autoridades nazis del campo procedieron a adecentarlo y a dotarlo de servicios de todo tipo, incluso con áreas de entretenimiento: cine, cafés y hasta un teatro (Farré y Schubert, 2009, p. 65-83). Los delegados del CICR fueron obligados a seguir un circuito dentro del campo previamente establecido y solo pudieron hablar con algunos internos convenientemente aleccionados y coaccionados por las autoridades del campo. Unos meses antes, en septiembre de 1943, y para reducir el hacinamiento de Terezin, 5.000 judíos del gueto fueron deportados a Auschwitz. Allí no fueron exterminados inmediatamente, pues las autoridades de Terezin temían que la delegación del CICR deseara hablar con alguno de los deportados a Polonia. Por esa razón en Auschwitz fueron alojados provisionalmente en uno de los "campos familiares" y a los niños no se les asesinó inmediatamente, sino que se les permitió vivir con uno de los padres (hombres y mujeres vivían separados). A las familias deportadas a Auschwitz se les pedía que enviaran postales y cartas a sus parientes y conocidos en Terezin para reforzar la idea de humanitarismo también en Auschwitz, a donde el CICR todavía no había podido acceder. Una vez terminada la visita de inspección a Terezin, los 5.000 judíos que habían sido deportados a Auschwitz fueron asesinados en las cámaras de gas (Rees, 2017, p. 445).

\footnotetext{
23 Artículo "Crisis of Confidence" de Caroline Moorehead en el Financial Times (18/06/2005): https://www.icrc.org/en/doc/resources/documents/article/other/6dzk8m.htm (web consultada: 30 de junio de 2021).
} 
En abril de 1945, el Dr. Otto Lehner y un delegado del CICR (Paul Dunant) fueron admitidos de nuevo en el gueto $y$, una vez más, quedaron sorprendidos al encontrar condiciones aparentemente tan buenas para los deportados. La propaganda nazi de Goebbels utilizó ampliamente la visita del CICR a Terezin, llegando incluso a rodar una película documental que fue estrenada durante últimos meses de guerra ${ }^{24}$.

El 5 de mayo de 1945, Terezin fue puesto formalmente bajo el control del CICR y fue entonces cuando el engaño del "Paraíso de Heydrich" finalmente fue descubierto. Pocos meses antes algunas autoridades nazis, con Himmler a la cabeza, habían iniciado negociaciones para liberar contingentes de prisioneros a cambio de contraprestaciones políticas o económicas. En aquellas conversaciones destacó Jean-Marie Musy, ex presidente sueco que negoció la evacuación de Terezin de un primer contingente de 1.200 prisioneros judíos que llegaron a Suiza en febrero de 1945 (Farré, 2012, p. 1394). A las mujeres se les pidió que se maquillaran, peinaran y vistieran bien "para tener buen aspecto a su llegada a Suiza” (Rees, 2017, p. 514). Pocas semanas más tarde, el vicepresidente de la Cruz Roja Sueca, el Conde Folke Bernadotte se reunió con Himmler y obtuvo el permiso para liberar a 4.700 prisioneros escandinavos pensando que con aquel "contrato" podría negociar una paz separada con los aliados occidentales (Navarro, 2010, p. 289). A finales de abril de 1945, a escasos días del armisticio, Folke Bernadotte empleó los camiones del CICR para evacuar a 2.900 mujeres del campo de concentración de Ravensbrück (Farré, 2012, p. 1394). Es precisamente el propio Folke Bernadotte quien en sus memorias vuelve a recordar, una vez, la importancia de la neutralidad: "repetidamente he sostenido el principio básico de que, en cualquier circunstancia, las organizaciones de la Cruz Roja deben evitar a toda costa verse mezcladas en la política internacional si desean actuar con libertad” (Bernadotte, 1948, p. 190).

\section{Impacto del genocidio en la evolución de los principios del CICR |}

La experiencia del CICR durante la SGM y especialmente su silencio con respecto al genocidio ha motivado como hemos visto un debate rico, lleno de matices jurídicos, éticos y operacionales. Por un lado, y desde un punto de vista puramente logístico, el CICR realizó una increíble labor humanitaria durante la SGM: sus delegados realizaron 11.000 visitas a prisioneros, proporcionaron 445.702 toneladas de ayuda y registraron y asistieron a 30 millones de personas de una forma u otra. $Y$ todo esto, con escasos recursos y con una absoluta falta de experiencia en el nuevo tipo de "guerra total" que estaba arrasando el mundo. Este es un éxito impresionante del humanitarismo que no sería justo olvidar y por esa razón en 1944, Max Huber fue galardonado con el Premio Nobel de la Paz.

Por otro lado, y desde un punto de vista ético-jurídico, el CICR comprobó las consecuencias de aplicar una neutralidad radical y como consecuencia de ello a lo largo

\footnotetext{
${ }^{24}$ Theresienstadt - Ein Dokumentarfilm aus dem jüdischen Siedlungsgebiet, dirigida por Kurt Gerron y asesinado en Auschwitz pocos meses después junto con el resto de actores de la película.
} 
de los años ha ido adoptando algunas medidas que aclararon algunos de sus principios más controvertidos y reforzaron el DIH, del que son custodios:

1. En 1949 se revisaron y actualizaron los tres Convenios de Ginebra, agregando el Convenio IV (civiles) y en 1977 los dos Protocolos adicionales, comunes a los cuatro convenios. Este corpus convencional conforma en la actualidad la base del DIH.

2. En 1966, el CICR aprobó su Carta de Principios Humanitarios, que a partir de entonces ha sido la principal referencia para el resto de organizaciones humanitarias que operan en zonas de conflicto. Los nuevos principios humanitarios establecen claramente que la "neutralidad" y la "imparcialidad" son esenciales para cumplir con la máxima prioridad del CICR que es el acceso a las víctimas (Kellenberger, 2004, p. 597) pero ciertas extremas circunstancias exigen algún tipo de "declaración pública que no necesariamente supondrá una amenaza para el acceso del CICR a las víctimas" (Kellenberger, 2004, p. 606). Esta ligera evolución ha supuesto que, aunque la neutralidad sigue siendo un principio fundamental del CICR, se hayan realizado algunas denuncias públicas del CICR contra crímenes de guerra; como sucedió en los casos de Bosnia y Herzegovina (agosto de 1992), Ruanda (28 de abril de 1994) o Kosovo (septiembre de 1998). En la actualidad la "política de discreción" del CICR es menos rígida que en el pasado, pero continúa siendo el signo distintivo de esta organización internacional.

3. Finalmente, el reconocimiento público por parte del CICR de su "gran fracaso" a causa de su silencio ante el genocidio es también la mejor prueba de su responsabilidad ${ }^{25}$. Las autocríticas de Peter Maurer en calidad de presidente del CICR (28 de abril de 2015) o de Rudolf Seiters en 2008 como presidente de la DRK son solo algunos ejemplos del análisis interno del CICR y de su capacidad para mejorar su mandato humanitario aprendiendo las lecciones del pasado. En palabras de Bernard Kouchner, antiguo delegado del CICR durante la Guerra de Biafra (1968) y posteriormente fundador de Médicos Sin Fronteras (Kouchner, 1991, p. 283):

La Cruz Roja Internacional conocía la existencia y el uso de los campos nazis y optó por callarse. Las justificaciones para este encubrimiento elevan la vergüenza a un nivel sin precedentes. Aquellos que compartieron este secreto tan terrible no intentaron intervenir.

\section{| Conclusiones |}

Según lo que hemos ido viendo, podemos concluir identificando las seis razones principales para que el CICR decidiera no denunciar públicamente el genocidio:

1. Vacío legal y convencional para proteger a la población civil en tiempo de guerra. Las dos únicas convenciones del CICR existentes (1929) antes de la SGM solo se ocupaban de los heridos y de los prisioneros de guerra, pero no de la población civil. El Borrador de Tokio (1934) nunca llegó a entrar en vigor y cuando se aplicó fue por analogía. Por otra parte, el Borrador, excluía de su ámbito de aplicación a la inmensa mayoría de

${ }^{25}$ Es exactamente así como el propio CICR denomina a este periodo ("Great Failure”) y así aparece en su página web al conmemorar en 1995 el $60^{\circ}$ aniversario de la liberación de Auschwitz (web consultada el 30 de junio de 2021): https://www.icrc.org/en/doc/resources/documents/statement/68zeb2.htm. 
civiles que, aun siendo alemanes o estando sometidos a las potencias del Eje, eran perseguidos y exterminados por sus propios gobiernos ${ }^{26}$. Habría que esperar hasta 1949 para que la Convención IV de Ginebra contemplara expresamente a los civiles como una nueva categoría protegida de "no combatientes".

2. Coherencia de la confidencialidad con algunos principios humanitarios que inspiraron el CICR durante el periodo de entreguerras y muy especialmente con el principio de neutralidad interpretado de manera estricta. La regla de confidencialidad sigue en la actualidad plenamente vigente (Ku y Bru, 2003, p. 56-72). El precio a pagar por tener una SNCR en cada país fue "no establecer unos estándares demasiado altos para la admisión de las Sociedades Nacionales, ya que una aplicación estricta de los principios liberales del humanitarismo podría romper el carácter universal de la Cruz Roja" (Sandoz, 2007). Dicho de otro modo, los principios de la Cruz Roja fueron interpretados con laxitud para dar cabida al mayor número posible de Sociedades Nacionales, incluso aun cuando muchas de ellas - como la DRK - estuvieran en las antípodas de los principios humanitarios o directamente los violaran.

3. Falta de información clara y concluyente hasta 1941 sobre el exterminio sistemático nazi contra los judíos y otros colectivos. Aunque es indudable, como hemos explicado, que a partir de 1933 el CICR contaba con numerosas pruebas acerca de la persecución y crímenes contra los judíos y otros grupos de la población civil, su reducida estructura, su escasa profesionalización hasta el inicio de la SGM y la nula colaboración de las SNCR en aquellos países controlados por el Eje (a los que también se sumó la URSS) hicieron extremadamente difícil una operativa coordinada y eficaz. Por otra parte, esta crítica es también extensible al resto de aliados beligerantes - no solo al neutral CICR - quienes, a pesar de contar con información contrastada sobre el genocidio no llegaron a vislumbrar su verdadero alcance, no lo priorizaron frente a las condiciones de vida de sus propios nacionales prisioneros $y$ en consecuencia tampoco lo denunciaron públicamente hasta el 17 de diciembre de 1942.

4. La ambigua relación del CICR con las SNCR. La desinformación acerca del genocidio creemos que fue agudizada, además, por la propia estructura internacional de la Cruz Roja Internacional ${ }^{27}$, integrada a la sazón por el conjunto de SNCR oficialmente reconocidas, por la Federación Internacional de Sociedades de la Cruz Roja y por el CICR. Este entramado de organizaciones superpuestas y en ocasiones con funciones poco claras suscitó rivalidades y tensiones recíprocas entre ellas y frente a un CICR poco proclive a renunciar a la soberanía suiza sobre el gran mandato humanitario consagrado por Dunant en 1863 pero al mismo tiempo incapaz de imponer su autoridad sobre las Sociedades Nacionales que se desviaran del mandato humanitario fundacional ${ }^{28}$. En el periodo de entreguerras la actitud distante y el unilateralismo de

\footnotetext{
${ }^{26}$ Por "gobiernos" nos referimos no solamente a la Alemania del Tercer Reich sino también a los gobiernos de países aliados (Italia, Hungría, Rumania, etc.) u ocupados (Polonia, Lituania, Francia, Bélgica, etc.) cuya participación activa fue determinante para el desarrollo del Genocidio.

${ }^{27}$ Actualmente se denomina Movimiento Internacional de la Cruz Roja y la Media Luna Roja.

${ }^{28}$ En 1863, Dunant crea en Ginebra el Comité Internacional de Socorros a los Militares Heridos, o Comité de los Cinco, llamado a partir de 1880 como Comité Internacional de la Cruz Roja (CICR). En 1863, en conferencia internacional con participación de 16 Estados, se acordó la creación de comités nacionales que actuarían como sociedades voluntarias de socorro para suplir las carencias
}

SHJ, 2022, 2(I), pp. 128-152. ISSN: 2792-3967 
Suiza y del CICR era difícil de asumir por la comunidad internacional. Aunque el CICR insistió en la necesidad de una relación más estrecha con las Sociedades Nacionales promoviendo la creación de una Federación de la Cruz Roja en 1920, su discurso federativo parecía más retorico que real pues el CICR en aquel tiempo percibía a la Federación como una pérdida de poder e influencia helvética. Con la creación en 1928 de los Estatutos del Movimiento Internacional de Cruz Roja, se confirmó la absoluta independencia y soberanía del $\mathrm{ClCR}$ con respecto al Movimiento. Las relaciones de ambas organizaciones, aunque nominalmente coordinadas, no fueron nada fáciles, ni amistosas (Forsythe, 2005, p. 36).

5. La ambigua relación entre el CICR con Suiza. El Gobierno suizo durante la SGM estuvo firmemente comprometido con una política de neutralidad ya que su limitado poder militar sumado a la proximidad geográfica de una Alemania expansiva y beligerante hacía temer a sus gobernantes una inminente invasión por parte del ejército alemán. En 1942 - año en el que el CICR adoptó en Ginebra el "pacto de silencio" - Suiza estaba virtualmente rodeada por los ejércitos de eje y temían una invasión ${ }^{29}$. En aquella difícil coyuntura internacional, el Gobierno suizo apoyó generosamente a una organización humanitaria como el CICR que - por asociación de ideas - reflejaba perfectamente su propia neutralidad. En 1942 el 55\% del presupuesto del CICR provenía del gobierno federal de Suiza, lo que da una idea de la dependencia económica del CICR con respecto al Gobierno helvético. Esa dependencia económica de un gobierno creemos que es un indicio de la erosión del principio humanitario de independencia que, como hemos visto, implica que "la intervención humanitaria se desempeñara sobre la base de las propias decisiones de la organización, al margen de condicionamientos políticos tanto en sus países de origen como en los que actúe". Y esta es otra de las grandes contradicciones del silencio del CICR ante el genocidio pues mientras, por una parte, tal silencio se fundaba en el principio de neutralidad, por otra se estaba erosionando el principio de independencia al seguir casi al pie de la letra los intereses políticos del Gobierno suizo. En 1936 Max Huber, presidente del CICR, escribió: "queremos una Suiza neutral y una Cruz Roja neutral" (Huber, 1936).

Aunque es cierto que el CICR tuvo un papel esencial en el cuidado de las víctimas y prisioneros de la guerra, su neutralidad estricta y su falta de independencia al depender financieramente del Gobierno suizo fueron dos grandes debilidades que afectaron al desarrollo futuro de la organización (Forsythe, 2005, p.14-15).

6. Pragmatismo. Ante el dilema ético que se le planteaba al CICR en donde se ponían en juego, y de forma excluyente, varios principios, la organización optó por dar prioridad al principio de humanitarismo o acción benefactora sobre algunas víctimas (prisioneros y heridos de guerra) frente otras: los deportados a los campos de exterminio, principalmente judíos (Mathur, 2008, p. 7). De este modo, y aun siendo conscientes de que su neutralidad estricta (pacto de silencio) estaba desasistiendo a

de los servicios sanitarios nacionales en caso de conflicto. En esa misma conferencia de 1880 se acordó igualmente el uso del emblema y símbolo de una cruz en color rojo sobre fondo blanco.

${ }^{29}$ Otros estados neutrales como España o el Estado del Vaticano también desarrollaron una política internacional ambigua y oscilante entre la no beligerancia y la neutralidad con los diversos países enfrentados y a medida que fue evolucionando el conflicto. 
numerosas víctimas civiles, el CICR y sus delegados pudieron realizar un trabajo humanitario enorme con millones de víctimas del conflicto. Dicho de otro modo, el CICR creyó que si hubiera denunciado públicamente los crímenes nazis sus delegados jamás habrían sido autorizados a acceder a los campos de prisioneros de guerra y con ello no solo no habrían impedido el exterminio, sino que "tampoco habrían podido acceder a más de dos millones de prisioneros y heridos de guerra" tal y como proclamó el presidente del CICR (Kellenberger, 2004, p. 598). Algunos autores discrepan de esa interpretación y creen que el CICR debió denunciar públicamente (Favez, 1999, p. 282 y Kellenberger, 2004, p. 606), aunque especular sobre lo que pudo haber pasado y no sucedió excede el objetivo de ese artículo.

Sin embargo, el reconocimiento explícito por parte del CICR de estos errores durante la SGM ha suscitado la paulatina evolución del principio humanitario de neutralidad por parte de la propia Cruz Roja y de otros actores humanitarios, cuya actuación ante violaciones más recientes del DIH (Bosnia, Abu Grai, Guantánamo, Ruanda, etc.) ha sabido conjugar la neutralidad y confidencialidad con un mínimo de incidencia política tras sus inspecciones e informes $y$, sobre todo, gracias su enorme legitimidad moral ante la mayoría de naciones (Bussmann y Schneider, 2010, p. 3).

\section{| Referencias |}

Blázquez, F., Devesa del Prado, A. y Cano, M. (1999). Diccionario de Términos Éticos. Editorial Verbo Divino.

Bussmann, M. y Schneider, G. (2010). A Porous Humanitarian Shield: The Laws of War, the Red Cross, and the Killing of Civilians. The Review of International Organizations, 11(3), 337-359.

Cuerda Galindo, E. (2016). Cuando la medicina no cura: la participación de personal sanitario en torturas, genocidios y experimentos al margen de los códigos éticos. Delta.

Dunant, H. (1862). Un recuerdo de Solferino. Imprenta de Jules-Guillaume Fick.

Durand, A. (1984). From Sarajevo to Hiroshima: History of the ICRC. Henry Dunant Institute.

Farré, S. y Schubert, Y. (2009). L'illusion de l'objectif. Le délégué du CICR Maurice Rossel et les photographies de Theresienstadt. Le Mouvement Social, (2), 65-83.

Farré, S. (2012). The ICRC and the detainees in Nazi concentration camps (1942-1945). International Review of the Red Cross 94 (888), 1381-1408.

Favez, J-C. (1989). 1942: le Comité international de la Croix-Rouge, les déportations et les camps. Vingtième Siècle. Revue d'histoire, (21), 45-56.

Favez, J-C. (1999) Red Cross and the Holocaust. Cambridge University Press.

Folke Bernadotte, C. (1948). Memorias. Editorial Mateu. 
Forsythe, D. (2005) The Humanitarians. The International Committee of the Red Cross. Cambridge University Press.

Huber, M. (1936). Red Cross and Neutrality. International Review of the Red Cross, 209, 353-363.

ICRC. (1948). Report of the International Committee of the Red Cross on its Activities during the Second World War. ICRC.

Junod, M. (1951). Warriors without weapons. Jonathan Cape.

Kant, M. (1921). Fundamentación de la Metafisica de las Costumbres. Calpe.

Kellenberger, J. (2004). Speaking out or remaining silent in humanitarian work. International Review of the Red Cross, 86 (855).

Kissinger, H. (1996). Diplomacia. Ediciones B.

Kouchner, B. (1991). Le malheur des autres. Odile Jacob.

$\mathrm{Ku}$, Ch. y Caceres Brun, J. (2003). Neutrality and the ICRC Contribution to Contemporary Humanitarian Operations. International Peacekeeping 10(1), 56-72.

Macrae, J. (1996). The Origins of Unease: Setting the Context of Current Ethical Debates. En Ethics in Humanitarian Aid. Non-Governmental Organisations Forum. ECHOVOICE December 9-10, 27-36.

Mathur, R. (2008). The Ethical Witness: The ICRC. YCISS Working Paper, 47.

Moorehead, C. (1988). Dunant's Dream: War, Switzerland and the History of the Red Cross. Harper Collins.

Moreillon, J. (1973). Le Comite' International de la Croix-Rouge et la protection des de'tenus politiques. Institut Henry Dunant.

Morgenbrod, B. y Merkenich, S. (2008). Das Deutsche Rote Kreuz unter der NS-Diktatur 1933-1945. Verlag Ferdinand Schöningh.

Navarro, F. (2010). Diccionario Biográfico de Nazismo y III Reich. Ed. Última Línea.

Navarro, F. y Sichar, G. (2019). ¡Eureka, Valores! Principios básicos de ética para las organizaciones. Ed. Última Línea.

Navarro, F., Sichar, G y Cuerda, E. (2018). El Delirio Nihilista: un ensayo sobre los totalitarismos, nacionalismos y populismos. Ed. Última Línea.

Pérez de Armiño, K. (2002). Diccionario de Acción Humanitaria y Cooperación al Desarrollo. Icaria/Hegoa.

Pictet, J. (1966). The Principles of International Humanitarian Law. International Review of the Red Cross, 6(66), 455-469.

Rees, L. (2017) El Holocausto. Ed. Crítica. 
RICR. (1991). Campaña mundial para la protección de víctimas de la guerra. Revue Internationale de la Croix-Rouge, 789, 327.

Rodriguez-Villasante y Prieto, J.L. y López Sánchez, J. (2017). Derecho Internacional Humanitario. Tirant Lo Blanc.

Sandoz, Y. (2007). Max Huber and the Red Cross. The European Journal of International Law, 1 (1).

Slim, H. (2001). Humanitarianism and the Holocaust: Lessons from ICRC's Policy towards the Jews. The International Journal of Human Rights, 5 (1).

Vonèche Cardia, I. (2012). Neutralité et engagement. Les relations entre le Comité international de la Croix-Rouge et le gouvernement suisse (1938-1945), SHSR. Société d'histoire de la Suisse romande.

Warner, D. (2005). Naming and Shaming: The ICRC and the Public/Private Divide Journal of International Studies, 34(2), 459.

\section{| Nota biográfica |}

Fernando Navarro García (Valencia, 1964). Licenciado en Derecho y doctor en Humanidades por la Universidad Rey Juan Carlos. Trabajó durante diez años en el sector privado. En 2001 fue cooperante en Angola, en un proyecto humanitario en un país en guerra civil. Posteriormente fue directivo en una importante ONG internacional. Desde 2015 es presidente del Centro de Investigaciones sobre los Totalitarismos y Movimientos Autoritarios (CITMA) y director del Instituto de Estudios para la Ética y la responsabilidad Social de las Organizaciones (INNOVAÉTICA). Ha codirigido varios títulos propios de la UNED y ha sido profesor asociado en la Universidad Carlos III de Madrid. Es autor o coautor de una decena de libros sobre los totalitarismos (Diccionario Biográfico de nazismo y III Reich, El Fenómeno Socialista, El Delirio Nihilista: un ensayo sobre los totalitarismos, nacionalismos y populismos); ética aplicada (Responsabilidad Social Corporativa: Teoría y Práctica, ¡Eureka, valores!) o la gestión empresarial. 